\title{
Validação de uma bateria de testes para avaliação da autonomia funcional de adultos com lesão na medula espinhal
}

CDD. 20.ed. 796.019

796.03
Camilla Yuri KAWANISHI*

Márcia GREGUOL*
*Centro de Educação

Física e Esporte,

Universidade Estadual

de Londrina.

\section{Resumo}

0 presente estudo teve como objetivo criar e validar uma bateria de testes motores relacionados à atividade da vida diária (AVD), com o intuito de avaliar a independência funcional de indivíduos com lesão na medula espinal. Para tanto, foram selecionados 22 sujeitos por conveniência, com idades variando entre 20 e 53 anos. Esses indivíduos foram submetidos à realização de uma bateria de testes, a qual passou por processo de verificação da validação por conteúdo, objetividade e reprodutibilidade. Os dados foram tratados através de estatística descritiva, Análise de Variância (ANOVA- "one-way"), Coeficiente de Correlação Intraclasses e teste t-Student. Adotou-se $\alpha=5 \%$. Os principais resultados demonstraram que os testes que compõe a bateria possuem descrição clara, relacionam-se com AVD e possuem aplicabilidade, o que torna válido seu conteúdo. Além disso, todos os testes demonstraram alto grau de objetividade $(p=1,00$ e $F=0,00)$ e reprodutibilidade $(\mathrm{CCl}>0,85)$. A elaboração desta bateria de testes especificos para pessoas com lesão na medula espinhal pode ser uma ferramenta útil para avaliar de forma efetiva e com qualidade alguns parâmetros relevantes do seu dia a dia, de modo a analisar a independência dos sujeitos.

PalAVRAS-Chave: Lesão medular; Deficiência motora; Medidas e avaliação; Validação.

\section{Introdução}

Segundo estimativa da Organização das Nações Unidas (ONU) cerca de $10 \%$ da população mundial vive com algum tipo de deficiência. Em números esse percentual equivale a aproximadamente 650 milhôes de pessoas. No Brasil o coeficiente de incidência de lesão traumática é desconhecido e não existem dados precisos sobre sua incidência e prevalência, uma vez que esta condição não está sujeita a notificação $0^{1-3}$.

Dados epidemiológicos apontam o crescente aumento da violência urbana e consequentemente $o$ número de casos de indivíduos com lesão da medula espinal. Esta violência caracteriza-se principalmente por acidentes com arma de fogo, automobilísticos e mergulhos, que faz entre suas maiores vítimas os homens jovens $\mathrm{s}^{4-5}$. Vários estudos, como os de VENTURINI et al. ${ }^{6}$ e GARMA et al. ${ }^{7}$, têm demonstrado alta prevalência de pessoas com lesão da medula espinal que apresentam relativa dependência de terceiros para realizar tarefas cotidianas. Essas tarefas cotidianas, também denominadas atividades básicas da vida diária (ABVDs) e atividades instrumentais da vida diária (AIVDs), incluem habilidades como as de se comunicar, vestir, arrumar, tomar banho, locomover-se e gerenciar a casa. Dependendo do nível da lesão, o indivíduo apresentará diferentes níveis de dependência. Pessoas com tetraplegia em nível alto (C1-C4) poderão apresentar dependência à maioria das atividades, enquanto aquelas com tetraplegia mais baixa (C5-C8) podem apresentar maior grau de independência, o que pode ser potencializado através do uso de órteses adequadas ou equipamentos adaptados. Indivíduos com paraplegia deveriam ser capazes de realizar as atividades do dia-a-dia de maneira independente.

Considerando como fator relevante a independência funcional de pessoas com lesão medular, estudos têm sido realizados ${ }^{9-11}$ no intuito de analisar possíveis fatores de influência na realização das atividades básicas e instrumentais da vida diária. Nesse contexto, faz-se necessária a criação de instrumentos que 
contemplem a avaliação da independência de modo prático, confiável e com baixo custo, sempre levando em consideração a individualidade dessas pessoas.

$\mathrm{O}$ presente estudo se justifica pela crescente necessidade de criação de baterias de testes que avaliem pessoas com lesão da medula espinal em seu contexto, respeitando suas restrições e possibilidades. A criação e validação de uma bateria de testes possibilitariam a detecção do nível de capacidade funcional, a prescrição individualizada de exercícios

\section{Método}

Foram selecionados por conveniência 22 indivíduos, sendo 20 homens e duas mulheres, todos com idades variando entre 20 e 53 anos $(33,18 \pm$ $9,42)$. Todos os participantes possuíam lesão da medula espinal em níveis torácicos ou lombares, sem acometimento da função muscular dos membros superiores que atenderam aos seguintes critérios:

- Critérios de inclusão:

- Ter passado por processo de reabilitação;

- Ter no mínimo um ano de lesão;

- Ter lesão em nível torácico e/ou lombar; e

- Ter concordado em participar da pesquisa, assinando o Termo de Consentimento Livre e Esclarecido.

- Critérios de exclusão:

- Apresentar outra condição física e/ou comprometimento intelectual que dificulte a realização dos testes propostos;

- Ter lesão em nível cervical ou T1 (primeira vértebra torácica); e

- Recusar-se a participar do estudo após os esclarecimentos.

Para obtenção dos dados sobre as características gerais de cada indivíduo foi proposto aos mesmos que respondessem a uma anamnese, não validada, criada pelas próprias autoras da pesquisa e composta por questóes que abordaram informaçóes gerais sobre sua saúde (presença de comorbidades como: hipertensão, diabetes, úlceras de pressão e utilização de medicamentos controlados), a deficiência (tipo, tempo e causa da lesão), e possíveis restriçóes para a execução de qualquer uma das tarefas que compunha a bateria de testes (dificuldade de entendimento e/ou comprometimento físico que impedisse a execução dos movimentos propostos). e o acompanhamento no processo de reabilitação motora após a lesão, uma vez que critérios de validação para os instrumentos atuais que avaliam a deficiência não possuem um padrão ouro ${ }^{12}$. Nesse sentido, o objetivo deste estudo foi criar e validar uma bateria de testes motores relacionados às atividades da vida diária (básicas e instrumentais), somente para pessoas com paraplegia, de modo a avaliar de forma efetiva a independência funcional de pessoas com lesão da medula espinal.

Foi solicitado também que esses mesmos indivíduos respondessem a um instrumento que mensurasse seu nível de atividade física, fator que poderia influenciar os resultados dos testes da bateria proposta. Optou-se pelo Questionário Internacional de Atividade Física (IPAQ), na versão curta, de mais fácil aplicação e análise com algumas questôes adaptadas para a realidade de pessoas com lesão medular, especialmente no que tange à locomoção em cadeira de rodas. Os resultados do IPAQ foram categorizados em dois níveis, de acordo com o tempo total gasto em atividades físicas ao longo dos sete dias, sendo que indivíduos que tiveram resultados menores que 150 minutos por semana foram classificados como insuficientemente ativo e aqueles com mais que 150 minutos por semana, classificados como ativo. Foi feita a opçáo pela versão curta do IPAQ, com adaptaçóes para a realidade de pessoas com lesão medular, pois esta forma é geralmente melhor aceita pelos participantes e é recomendada para estudos nacionais de prevalência com possibilidade de comparaçóes internacionais ${ }^{13}$.

Os sujeitos do estudo foram recrutados entre os participantes dos projetos voltados para pessoas com lesão da medula espinal desenvolvidos pelo Centro de Educação Física e Esporte e pelo Hospital Universitário da Universidade Estadual de Londrina, Paraná. Todos os sujeitos leram e assinaram o Termo de Consentimento Livre e Esclarecido (TCLE) para participação no estudo. A pesquisadora colocou-se à disposição para quaisquer esclarecimentos e se comprometeu em divulgar individualmente os resultados e interpretação da bateria de testes. $\mathrm{O}$ estudo obteve aprovação do Comitê de Ética em Pesquisa envolvendo Seres Humanos da Universidade Estadual de Londrina, por meio do parecer $n^{\circ} 159 / 2011$. 


\section{Procedimentos para elaboração da bateria de testes}

A elaboraçáo dessa bateria de testes foi desenvolvida em duas fases: a) criação da bateria (escolha das atividades que foram selecionadas para compor os testes e dos critérios de pontuação); b) validação da bateria, através da determinaçâo da validação por conteúdo e dos graus de objetividade e fidedignidade dos testes.

Para selecionar as atividades que comporiam a bateria de testes de independência funcional, 10 pessoas com lesão da medula espinal foram convidadas a escrever, durante uma semana, um relatório com as atividades do cotidiano e a dificuldade apresentada para a realização das mesmas. Com base na análise destes relatórios foram selecionadas as atividades mais desempenhadas e as de maior dificuldade de execução. Logo após a seleçáo, os testes foram criados e adaptados para serem realizados em cadeira de rodas. Posterior à fase de elaboração, procedeu-se à aplicação dos testes em dois indivíduos com lesão da medula espinal, atletas de basquete em cadeira de rodas. $\mathrm{O}$ objetivo deste procedimento foi criar um "ranking" para a pontuação, bem como para classificar os níveis de independência em cada um dos testes que iriam compor a bateria. Os resultados obtidos pelos dois atletas passaram então a ser considerados como o referencial ideal de desempenho e, a partir deste, foram delimitados os outros referenciais. Dessa forma, conseguiu-se elencar escalas classificatórias com pontuaçôes para cada resultado relativo à independência funcional.

$\mathrm{O}$ processo de verificação da autenticidade científica da bateria de testes de atividades da vida diária foi composto pela determinação da validade por conteúdo, objetividade e fidedignidade. A validade por conteúdo foi determinada por meio da apreciação dos testes criados. Cinco especialistas na área de atividade física adaptada analisaram a clareza da descrição dos testes, bem como sua aplicabilidade e relação com atividades da vida diária desse tipo de populaçáo e emitiram suas opinióes em formulário próprio para cada teste (adaptado de AndreotTI \& Окима $)^{14}$.

Para fins de avaliação de fidedignidade e objetividade, a bateria foi aplicada simultaneamente por três avaliadores, que o fizeram de forma independente e não tiveram contato entre si durante a aplicação. E aplicada pelo mesmo avaliador em duas situaçóes distintas nos mesmos sujeitos, com um intervalo de aplicação que variou entre sete a 10 dias. Para auxiliar na aplicação da bateria de teste utilizou-se uma ficha de avaliação elaborada especialmente para este fim.
A objetividade de um instrumento de medida pode ser definida como o "grau em que se espera consistência dos resultados, quando o teste é aplicado ou anotado simultaneamente por diferentes avaliadores nos mesmos indivíduos”. Já a reprodutibilidade de um instrumento de medida, também conhecida como fidedignidade, é o "grau em que se espera que os resultados sejam consistentes ou reprodutivos, quando examinados pelo mesmo observador em dias diferentes, geralmente próximos entre si" ${ }^{15}$. O estudo de Gorgatti e BohmE ${ }^{16}$ e Rech et al. ${ }^{17}$ utilizaram a mesma metodologia empregada nesse estudo para fins de validação.

Após análise da autenticidade científica da bateria de testes, foram atribuídas notas que variaram entre zero a cinco pontos para cada teste selecionado (ANEXO 1). Dependendo do desempenho na execuçáo da tarefa o indivíduo poderia pontuar entre zero até a marca máxima de 27 pontos.

Em relação à pontuaçáo dos testes, o de suspensão em cadeira de rodas, resistência muscular de bíceps e tríceps, transpor degrau e teste de 400 metros variavam com pontuação de zero a três pontos. $\mathrm{O}$ teste de transferência da cadeira de rodas para outro assento poderia ser pontuado de zero a um. Os testes de alcance lateral, alcance lateral para baixo e alcance com rotaçáo de tronco variavam os escores de zero a dois pontos e apenas o teste de alcance frontal teve pontuação variando entre zero a cinco pontos. Desse modo, através da somatória dos pontos de cada teste foi elencada a categorizaçáo quanto à independência funcional de pessoas com lesão na medula espinhal, conforme mostra a TABELA 1.

TABELA 1 - Classificação da independência funcional da bateria de testes.

\begin{tabular}{ll}
\hline \multicolumn{1}{c}{ Pontuaçáo } & \multicolumn{1}{c}{ Descriçáo } \\
\hline $0-8$ pontos & Dependência total \\
$9-18$ pontos & Independência moderada \\
$19-27$ pontos & Independência total \\
\hline
\end{tabular}

Os testes foram aplicados no Centro de Educação Física e Esporte da Universidade Estadual de Londrina/PR. Avaliaçóes e reavaliaçóes foram realizadas sempre nos mesmos horários e locais, evitando deste modo possíveis interferências de fatores externos que atrapalhariam nos resultados do estudo.

Para efetuar a análise dos dados, na fase de seleção das atividades que comporiam a bateria de testes e na determinação da validade por conteúdo, foi utilizada a estatística descritiva (frequência de resposta, com 
valores percentuais). Para a verificação da objetividade da bateria de testes, foi utilizada Análise de Variância (ANOVA “one-way") entre os valores aferidos pelos três avaliadores, adotando-se significância $\mathrm{p}<$ 0,05 . Já a reprodutibilidade foi verificada por meio do Coeficiente de Correlação Intraclasses entre as

\section{Resultados}

Dos 22 indivíduos que fizeram parte da pesquisa, 20 (90,9\%) eram do sexo masculino e a faixa etária predominante (45,5\%) apresentou-se entre os 30 e 39 anos. Houve maior frequência de lesão do tipo completa $(68,19 \%)$ em nível torácico mais baixo (T9 e abaixo), contabilizando 59,1\% da amostra. Quanto ao tempo de lesão, a maioria dos participantes $(63,6 \%)$ reportou tempo superior a cinco anos. Em relação à classificaçáo quanto à sensibilidade e função motora, $68,2 \%$ dos participantes foram categorizados através da escala ASIA

TABELA 2 - Caracterização dos sujeitos. duas aplicações do teste. Análises de comparaçóes realizadas entre os grupos ativo e insuficientemente ativo foram feitas através do Teste $\mathrm{t}$-Student para amostras independentes, adotando-se também a significância $\mathrm{p}<0,05$. Para a análise dos dados foi utilizado o programa estatístico SPSS, versão 18.0.
$\mathrm{N}:$ número de indivíduos $\%$ : Percentual.

\begin{tabular}{|c|c|c|c|}
\hline & Variáveis & $\mathbf{N}$ & $\%$ \\
\hline \multirow{3}{*}{$\begin{array}{l}\text { V: número de indivíduos } \\
\%: \text { Percentual. }\end{array}$} & Sexo & & \\
\hline & Masculino & 20 & 90,9 \\
\hline & Feminino & 2 & 9,1 \\
\hline \multicolumn{4}{|c|}{ Faixa etária } \\
\hline & $20-29$ & 8 & 36,4 \\
\hline & $30-39$ & 10 & 45,5 \\
\hline & $40-49$ & 3 & 13,6 \\
\hline & $50-59$ & 1 & 4,5 \\
\hline & \multicolumn{3}{|l|}{ Tipo de lesáo } \\
\hline & Completa & 15 & 68,19 \\
\hline & incompleta & 7 & 31,81 \\
\hline & \multicolumn{3}{|l|}{ Nível de lesáo } \\
\hline & T3 - T8 & 9 & 40,9 \\
\hline & T9 - L1 & 13 & 59,1 \\
\hline & \multicolumn{3}{|l|}{ Tempo de lesáo } \\
\hline & 1 a 2 anos & 6 & 27,3 \\
\hline & 3 a 4 anos & 1 & 4,5 \\
\hline & 5 anos e mais & 15 & 68,2 \\
\hline & \multicolumn{3}{|l|}{ Nível de atividade física } \\
\hline & Ativo & 12 & 54,5 \\
\hline & Insuficientemente ativo & 10 & 45,5 \\
\hline
\end{tabular}

(American Spinal Injury Association) na classe ASIAA, $22,7 \%$ na classe ASIA B e o restante $(9,1 \%)$ na classe ASIA C. Em relação ao nível de atividade física, a maior parte dos indivíduos $(54,5 \%)$ foi classificada através do Questionário Internacional de Atividade Física (IPAQ) como fisicamente ativa. Ainda, em relaçáo ao nível socioeconômico, a maioria dos participantes $(54,5 \%)$ foi categorizada nas classes B1 e B2. A TABELA 2 reproduz os dados quanto à caracterização dos sujeitos do estudo de forma mais detalhada. 


\section{Seleção dos testes}

Os dados obtidos nos relatórios apresentaram várias atividades realizadas rotineiramente pelos indivíduos e o grau de dificuldade em executá-las. Dentre as mencionadas, fez-se uma seleção de atividades que poderiam ser realizadas em cadeira de rodas e que refletissem situaçóes cotidianas. Durante a seleçáo de todas as atividades que compuseram a bateria de testes procurou-se avaliar de forma efetiva a independência de pessoas com lesão medular, levando em consideração atividades da vida diária desempenhadas pelos sujeitos.

As atividades selecionadas foram: suspensão em cadeira de rodas por cinco segundos, transferência da cadeira de rodas para outro assento, resistência muscular de bíceps e tríceps, alcance funcional lateral, lateral para baixo, frontal e com rotação de tronco, transposiçáo de degrau e toque de cadeira de rodas por 400 metros. Todos os testes estão descritos detalhadamente no ANEXO 2.

Durante toda a fase de seleção das atividades que iriam compor a bateria de testes foram apontadas as justificativas para a escolha das mesmas. Optouse pelo teste de suspensão em cadeira de rodas por cinco segundos, pois este movimento é muito indicado às pessoas com lesão da medula espinal por evitar a ocorrência de úlceras de pressáo, sequela de impacto importante no seu cotidiano.

O segundo teste, o de transferência da cadeira de rodas para outro assento, foi escolhido por refletir a ideia de independência para a realização de atividades de cunho básico como ir ao banheiro, tomar banho e até mesmo deslocar-se da cadeira de rodas para a cama, em que o individuo necessita se deslocar de maneira efetiva de sua cadeira para outro assento qualquer.

A escolha dos testes de resistência muscular de bíceps e tríceps justificam-se por contemplar em sua execuçáo movimento mono articular de ângulo reduzido, importante na realização de atividades da vida diária e que repercute diretamente na independência funcional desses sujeitos. Já os testes de alcance funcional lateral, lateral para baixo, frontal e com rotação de tronco foram selecionados por possibilitarem a execução de alcance funcional em diferentes direçóes, viabilizando maior independência na realização das atividades da vida diária às pessoas lesão da medula espinal.
A locomoção realizada com eficiência, principalmente para pessoas com lesão da medula espinal, é extremamente importante por se traduzir em independência e efetividade em várias atividades realizadas durante $\mathrm{o}$ dia-a-dia. Locomover-se através do auxilio de uma cadeira de rodas nâo compreende apenas o deslocamento efetivo dessas pessoas, mas a transposiçáo de fatores externos como barreiras arquitetônicas, alteraçôes no tipo de solo e sua inclinaçáo. Tendo em vista a locomoçáo como atividade de vida diária e sendo ela indicador importante de independência, os testes de transpor degrau e tocar cadeira de rodas por um percurso de 400 metros também foram incluídos na bateria.

\section{Validação por conteúdo}

A validaçáo por conteúdo foi determinada por meio do parecer de cinco especialistas de reconhecido gabarito no assunto, sendo um mestre e quatro doutores nas áreas de atividade física adaptada e reabilitação, que emitiram opiniôes sobre a aplicabilidade dos testes que compunham a bateria, bem como sua efetividade em mensurar e classificar níveis de independência em pessoas com lesão medular. Os pareceristas preencheram os formulários anexados ao final de cada teste, respondendo questóes relacionadas à clareza na sua descrição, aplicabilidade e relação com as atividades da vida diária.

Quanto ao entendimento em relação à descrição dos testes (clareza), $80 \%$ dos pareceristas classificaram-nos como de muito fácil entendimento, $20 \%$ de fácil entendimento e nenhum deles apontou respostas classificando os testes como difícil ou muito difícil de entender.

$\mathrm{Na}$ análise dos resultados quanto à viabilidade de aplicaçáo dos testes, todos os pareceristas (100\%) classificaram-nos como muito viáveis. Quanto à relação dos testes com atividades de vida diária, nenhum dos pareceristas considerou a alternativa "náo" como resposta, ou seja, todos os testes foram considerados capazes de predizer a eficiência na realização das atividades de vida diária.

Todos os especialistas emitiram parecer favorável quanto ao conteúdo e aplicabilidade de todos os testes propostos, indicando que a bateria seria capaz de mensurar as variáveis que se propóe. Nesse sentido, os resultados apontaram que os testes têm uma descriçáo clara, possuem aplicabilidade e relação com atividades da vida diária, o que corroborou a validade de seu conteúdo. 


\section{Objetividade}

A fim de se verificar a objetividade da bateria proposta, três avaliadores fizeram as mensurações simultaneamente em todos os testes, que foram aplicados em dois momentos, com intervalo de sete a 10 dias. A análise de variância com um fator fixo e medidas repetidas (ANOVA "one-way") foi utilizada para análise de concordância entre os observadores, avaliando dessa forma a objetividade dos testes em validação. Os resultados não demonstraram diferença significativa $(\mathrm{p}=1,00$ e $\mathrm{F}=0,00)$ entre as aferiçóes realizadas pelos três avaliadores em nenhum dos testes propostos e no reteste, indicando boa concordância entre as médias e consistência dos resultados.

\section{Reprodutibilidade}

A reprodutibilidade foi verificada por meio do cálculo do Coeficiente de Correlação Intraclasses realizado com os dados obtidos em duas testagens distintas, com intervalo de sete a 10 dias entre elas. A reprodutibilidade foi verificada em todos os testes. A TABELA 3 apresenta os valores dos Coeficientes de Correlaçáo Intraclasses que indicaram excelente confiabilidade. Para a situação teste/reteste, observase que os valores de correlaçáo Intraclasses foram maiores que $0,85 \mathrm{em}$ todos os casos, indicando uma forte associação linear entre as variáveis.
TABELA 3 - Resultados dos Coeficientes de Correlação Intraclasses (CCI) em cada teste.

\begin{tabular}{ll}
\hline Testes & CCI \\
\hline Suspensão por cinco segundos & 1,00 \\
Transferência & 1,00 \\
Resistência muscular bíceps & 0,97 \\
Resistência muscular tríceps & 0,98 \\
Alcance lateral & 0,88 \\
Alcance lateral para baixo & 1,00 \\
Alcance frontal & 0,96 \\
Alcance com rotação de tronco & 1,00 \\
Transpor degrau & 1,00 \\
400 metros & 0,98 \\
\hline
\end{tabular}

\section{Resultados da bateria de testes}

Os resultados da bateria de testes obtidos através de sua aplicação em 22 sujeitos demonstraram que $86,4 \%$ dos avaliados possuem total independência para realização das atividades do dia-a-dia. Destes, $63,1 \%$ são fisicamente ativos e 36,9\% insuficientemente ativos. Os outros $13,6 \%$ foram categorizados com nível de independência elevada, mas não total, e eram representados apenas por indivíduos insuficientemente ativos. Nas TABELAS 4, 5 e 6 são apresentados os resultados gerais obtidos através $\mathrm{da}$ aplicação da bateria de testes.

TABELA 4 - Escore individual e classificação quanto à independência funcional.

\begin{tabular}{|c|c|c|c|c|}
\hline \multirow{16}{*}{$\begin{array}{l}\text { ID: Identificação do } \\
\text { sujeito. }\end{array}$} & ID & Nível da lesáo & Pontuaçáo & Classificaçáo \\
\hline & 1 & $\mathrm{~T} 7$ & 19 & Independência total \\
\hline & 2 & Т 12 & 26 & Independência total \\
\hline & 3 & $\mathrm{~T} 12$ & 27 & Independência total \\
\hline & 4 & $\mathrm{~T} 10$ & 26 & Independência total \\
\hline & 5 & T10 & 23 & Independência total \\
\hline & 6 & $\mathrm{~T} 12$ & 26 & Independência total \\
\hline & 7 & L1 & 27 & Independência total \\
\hline & 8 & T11 & 26 & Independência total \\
\hline & 9 & $\mathrm{~T} 10$ & 26 & Independência total \\
\hline & 10 & T12 & 26 & Independência total \\
\hline & 11 & T3 & 23 & Independência total \\
\hline & 12 & $\mathrm{~T} 10$ & 27 & Independência total \\
\hline & 13 & $\mathrm{~T} 3$ & 26 & Independência total \\
\hline & 14 & $\mathrm{~T} 4$ & 26 & Independência total \\
\hline & 15 & T4 & 22 & Independência total \\
\hline
\end{tabular}


TABELA 4 -Escore individual e classificação quanto à independência funcional (continuação).

\begin{tabular}{cccc}
\hline ID & Nível da lesão & Pontuação & Classificação \\
\hline 16 & T4 & 26 & Independência total \\
17 & T10 & 19 & Independência total \\
18 & T7 & 26 & Independência total \\
19 & T12 & 22 & Independência total \\
20 & T3 & 19 & Independência total \\
21 & T11 & 26 & Independência total \\
22 & T6 & 24 & Independência total \\
\hline
\end{tabular}

ID: Identificação do sujeito.

TABELA 5 - Porcentagem de escores obtidos na bateria de testes.

\begin{tabular}{lcccccc}
\hline \multirow{2}{*}{ Testes } & \multicolumn{7}{c}{ Pontuaçóes } \\
\cline { 2 - 7 } & $\mathbf{0}$ & $\mathbf{1}$ & $\mathbf{2}$ & $\mathbf{3}$ & $\mathbf{4}$ & $\mathbf{5}$ \\
\hline Suspensão por cinco segundos & - & - & - & $100 \%$ & $\mathrm{NA}$ & $\mathrm{NA}$ \\
Transferência & $4,5 \%$ & $95,5 \%$ & $\mathrm{NA}$ & $\mathrm{NA}$ & $\mathrm{NA}$ & $\mathrm{NA}$ \\
Resistência muscular bíceps & - & - & $4,5 \%$ & $95,5 \%$ & $\mathrm{NA}$ & $\mathrm{NA}$ \\
Resistência muscular tríceps & - & - & $4,5 \%$ & $95,5 \%$ & $\mathrm{NA}$ & $\mathrm{NA}$ \\
Alcance lateral & - & $9 \%$ & $91 \%$ & $\mathrm{NA}$ & $\mathrm{NA}$ & $\mathrm{NA}$ \\
Alcance lateral para baixo & - & - & $100 \%$ & $\mathrm{NA}$ & $\mathrm{NA}$ & $\mathrm{NA}$ \\
Alcance frontal & - & - & $4,5 \%$ & - & $77,3 \%$ & $18,2 \%$ \\
Alcance com rotação de tronco & $4,5 \%$ & - & $95,5 \%$ & $\mathrm{NA}$ & $\mathrm{NA}$ & $\mathrm{NA}$ \\
Transpor degrau & $13,6 \%$ & $18,2 \%$ & $4,5 \%$ & $63,7 \%$ & $\mathrm{NA}$ & $\mathrm{NA}$ \\
Tocar cadeira por $400 \mathrm{~m}$ & $4,5 \%$ & $4,5 \%$ & $27,3 \%$ & $63,7 \%$ & $\mathrm{NA}$ & $\mathrm{NA}$ \\
\hline
\end{tabular}

NA: não se aplica (-) Nenhum sujeito pontuou

TABELA 6 - Resultados descritivos da bateria de testes.

\begin{tabular}{lc}
\hline Testes & Média \\
\hline Resistência muscular bíceps (rep) & $25,9(6,8)$ \\
Resistência muscular tríceps (rep) & $25,4(7,8)$ \\
Alcance lateral (cm) & $28,2(6,9)$ \\
Alcance frontal (cm) & $46,6(9,7)$ \\
Tocar cadeira por $400 \mathrm{~m}(\mathrm{~s})$ & $206,6(69,1)$ \\
\hline
\end{tabular}

rep: número de repetições $\mathrm{cm}$ : centímetros s: segundos

\section{Discussão}

Os resultados obtidos por meio da seleçáo das atividades que compuseram a bateria de testes demonstram que os sujeitos do estudo apresentaram alto grau de independência funcional, inclusive no grupo insuficientemente ativo. É possível que a alta prevalência de lesão medular baixa e que a seleçáo amostral por conveniência tenham interferido neste achado, uma vez que a pesquisa fora realizada com pacientes de centros de reabilitação ou programas de atividade física.

Resultados convergentes aos encontrados foram observados por Durán et al. ${ }^{9}$, que avaliaram 13 pessoas, selecionadas também por conveniência, com lesão da medula espinal em níveis T3 (terceiro nível torácico) a T12 (12 nível torácico). Após a intervençáo de um 
programa de exercícios físicos, pode ser observada melhora nos parâmetros de independência de pessoas com lesão medular mais baixa quando comparado a lesões em níveis mais altos. Neste caso, a independência foi mensurada pré e pós-intervenção, através da Escala MIF (Medida de Independência Funcional). Em ambas as situaçóes foram observadas melhoria nos escores, no entanto em pessoas com lesão mais baixa os escores sobre a independência apresentaram-se mais significativos. Uma possível explicação colocada pelos autores é o fato de o tempo de lesão dos indivíduos que participaram do estudo ser a partir de seis meses. Além disso, lesões em níveis mais baixos acarretam em menos comprometimentos físicos e motores do que lesôes em níveis mais elevados.

A Escala MIF é um instrumento de avaliação da capacidade de pacientes com restriçóes funcionais de origem variada ${ }^{18}$, aplicável para pessoas com lesão medular, mas não específica a este tipo de população. Com tradução e validação para a língua brasileira é efetiva na avaliação quantitativa, a carga de cuidados demandada por uma pessoa para a realização de uma série de tarefas motoras e cognitivas ${ }^{19}$. Entre as atividades avaliadas estão os autocuidados, transferências, locomoção, controle esfincteriano, comunicação e cognição social, que inclui memória, interação social e resolução de problemas.

Em comparaçáo a bateria de testes proposta neste estudo e a escala MIF é relevante ressaltar que ambas não são instrumentos autoaplicáveis, e que necessitam de treinamento para sejam utilizadas de forma correta. No entanto, convergente, tem-se a escala estruturada através de questionamentos sobre as diferentes atividades básicas e instrumentais da vida diária e a bateria propondo testes específicos que avaliem atividades parecidas a aplicadas na escala.

A escassez de instrumentos específicos para pessoas com deficiência, mais especificamente para pessoas com paraplegia é uma realidade que necessita ser modificada. Nesse sentido, estudos têm sido realizados no intuito de sanar essa necessidade, ainda em processo. A escala SCIM (Spinal Cord Independence Measure) é um exemplo de instrumento criado especificamente para pessoas com lesão medular e que está sendo amplamente utilizada. Sua primeira versão foi publicada em 1997. É um instrumento que se propõe a mensurar a independência nas atividades cotidianas do paciente com lesão medular, ABVDs e AIVDs ${ }^{20}$. Suas principais vantagens em relação a outros instrumentos utilizados para avaliação funcional, especificamente na área da reabilitação são a sua sensibilidade a mudanças no desempenho de tarefas que são relevantes para pacientes com lesão medular e o fato de não mensurar apenas a carga de cuidados, mas também as conquistas, com relevância médica, psicológica e social para o paciente com lesão na medula espinal ${ }^{21}$. Consiste em três subescalas, três domínios, com 19 tarefas a serem avaliadas no total: autocuidado, manejo respiratório e esfincteriano e mobilidade. Pode ser aplicada em pacientes adultos e idosos e em diferentes grupos de lesão medular, tetraplegia, paraplegia, completa ou incompleta, com etiologias diferentes. Trata-se de um instrumento já validado internacionalmente, que deve ser aplicado por equipe designada de profissionais da saúde como fisiatria, enfermeiro, terapeuta ocupacional e fisioterapeuta ${ }^{22}$, com baixo custo, mas com demanda relativamente alta de tempo (30 minutos cada aplicação) e que ainda não foi traduzida nem validada para a realidade brasileira.

Nesse contexto, a bateria de testes proposta neste estudo visa a avaliação da independência funcional, fundamentada na realidade da cultura brasileira e pautada sobre testes específicos a essa população, testes estes executáveis e que refletem atividades corriqueiras dessas pessoas.

A partir dos resultados do presente estudo foi constatada a legitimidade científica da bateria que fora proposta, demonstrando que os testes são válidos, fidedignos e passíveis de serem reproduzidos. Sugerese, diante do exposto, a produçáo de novos trabalhos que faça uso dessa bateria em amostras não tão convenientes em que fosse possível uma discussão mais precisa sobre a eficácia do uso desse novo instrumento e sua aplicabilidade na avaliação da independência de indivíduos com lesão na medula espinal.

É válido ressaltar que estes dados são preliminares e que estudos posteriores devem ser realizados, comtemplando talvez, uma amostragem mais significativa (maior), incluindo também pessoas com lesóes em nível cervical e que não sejam recrutados de centros de reabilitação (amostra por conveniência).

Por fim, é importante ressaltar a necessidade da criação de instrumentos para a análise direcionada a cada tipo específico de deficiência. Este trabalho abordou apenas pessoas com paraplegia com o intuito de avaliar de forma efetiva padróes relacionados a essa população. A bateria de testes que foi proposta pode oferecer subsídios para o desencadeamento de açóes que visem à melhoria na independência.

Os resultados deste estudo permitiram concluir que a bateria de testes proposta possui validade de conteúdo, objetividade e fidedignidade. No 
entanto apresenta limitaçóes quanto à análise de desempenho ser feita apenas em nível quantitativo. Sugere-se que, juntamente com a aplicação desses testes, exista a preocupação de avaliar a forma com a qual os indivíduos desempenham tais tarefas, ou seja, a forma pela qual se adaptam a cada situação motora. Além disso, os resultados deste estudo ainda evidenciaram sobremaneira, que a criação de uma bateria de testes relacionados a atividades do cotidiano de pessoas paraplégicas é de extrema importância, na medida em que é capaz de detectar níveis de capacidade funcional e ser utilizada para avaliaçáo do desenvolvimento em busca da independência de uma maneira mais ampla.

\begin{abstract}
Validation of a test battery to assess functional autonomy of adults with spinal cord injury

The present study aimed to create and validate a battery of motor tests related to activities of daily life (ADL), in order to evaluate the functional independence of individuals with spinal cord injury. For this, were selected 22 subjects by convenience, aged between 20 and 53 years, which were submitted to a battery of motors tests. This battery was underwent to process of validation of content, objectivity and reproducibility. The data were analyzed by descriptive statistics, one-way ANOVA, Coefficient of Intraclasses Correlation and t-Student test. The $\alpha=5 \%$ was adopted. The main results shown that the tests of battery present clear description, they are related to ADL and they have applicability, making valid the battery content. Moreover, every tests have demonstrated high degree of objectivity $(p=1.00$ e $\mathrm{F}=0.00)$ and reproducibility $(\mathrm{CCl}>0.85)$. The formulation of this battery of specific tests for people with spinal cord injury can be a useful tool to evaluate some relevant parameters of their daily with effectiveness and quality, analyzing the subjects' independence.
\end{abstract}

KEY WORDS: Spinal cord injury; Motor disability; Measurements and evaluation; Validation.

\title{
Referências
}

1. Campos MF, Ribeiro AT, Listik S, Pereira CAB, Andrade Sobrinho J, Rapoport A. Epidemiologia do traumatismo da coluna vertebral. Rev Col Bras Cir. 2008;35:88-93.

2. Solino JL, Melo MFFV, Silva DHA. Traumatismos da coluna vertebral: avaliação da etiologia, incidência e frequência. Rev Bras Ortop. 1990;25:185-90.

3. Brasil. Ministério da Saúde. Diretrizes de atenção à pessoa com lesão medular. Brasília: MS; 2013.

4. Defino HLA. Trauma raquimedular. Medicina. 1999;32:388-400.

5. Gonçalves AMTG, Rosa LN, D’Angelo CT, et al. Aspectos epidemiológicos da lesão medular traumática na área de referência do Hospital Estadual Mario Covas. Arq Med ABC. 2007;32:64-6.

6. Venturini DA, Decésaro MN, Marcon SS. Alteraçóes e expectativas vivenciadas pelos indivíduos com lesão raquimedular e suas famílias. Rev Esc Enferm USP. 2007;41:589-96.

7. Garma SL, Kelly EH, Dararsh EZ, Vogel LC. Health-related quality of life after pediatric spinal cord injury. J Pediatr Psychol. 2011;36:226-36.

8. Atrice MB, Morrison SA, McDowell SL, Shandalov B. Lesão medular traumática. In: Umphred DA. Reabilitação neurológica. 4a ed. São Paulo: Manole; 2004.

9. Durán FS, Lugo L, Ramírez L, Eusse E. Effects of an exercise program on the rehabilitation of patients with spinal cord injury. Arch Phys Med Rehabil. 2001; 82:349-54.

10. Silva MCR, Oliveira RJ, Conceição MIG. Efeitos da natação sobre a independência funcional de pacientes com lesão medular. Rev Bras Med Esporte. 2005;11:251-6.

11. Galea MP, Dunlop SA, Davis GM, et al. Intensive exercise program after spinal cord injury (“Full-On”): study protocol for a randomized controlled trial. Trials. 2013;14:291. 
12. Furlan JC, Noonan V, Singh A, Fehlings MG. Assessment of disability in patients with acute traumatic spinal cord injury: a systematic review of the literature. J Neurotrauma. 2011;28:1413-30.

13. Matsudo S, Araújo T, Matsudo V, et al. Questionário Internacional de Atividade Fisica (IPAQ): estudo de validade e reprodutibilidade no Brasil. Rev Ativ Fís Saúde. 2001;6:5-14.

14. Andreotti RA, Okuma SS. Validação de uma bateria de testes de atividades da vida diária para idosos fisicamente independentes. Rev Paul Educ Fís. 1999;13:46-66.

15. Kiss MAPDM. Avaliação em educação física. São Paulo: Manole; 1987.

16. Gorgatti MG, Bohme MTS. Autenticidade científica de um teste de agilidade para indivíduos em cadeiras de rodas. Rev Paul Educ Fís. 2003;17:41-50.

17. Rech CS, Fermino RC, Hallal PC, Reis RS. Validade e fidedifnidade da escala de satisfação com a prática de atividade física em adultos. Rev Saúde Pública. 2011. Epub 2011 Fev 25.

18. Granger CV, Hamilton BB, Keith RA, Zielezny M, Sherwin FS. Advances in functional assessment for rehabilitation: in topics in geriatric rehabilitation. Rockville: Aspen; 1986.

19. Riberto M, Miyazaki MH, Sakamoto H, Jorge Filho D, Battistella LR. Reprodutibilidade da versão brasileira da medida de independência funcional. Acta Fisiatrica. 2000;8:45-52.

20. Takami MP, Figliolia CS, Tsukimoto GR, et al. Lesão medular: reabilitação. Acta Fisiatrica. 2012;19:90-8.

21. Fekete C, Eriks-Hooland I, Baumberger M, et al. Development and validation of a self-report version of the spinal cord independence measure (SCIM III). Spinal Cord. 2013;51:40-7.

22. Catz A, Itzkovich M, Agranov E, Ring H, Tamir A. The spinal cord independencemeasure (SCIM): sensitivity to functional changes in subgroups of spinal cord lesion patients. Spinal Cord. 2001;39:97-100.

ANEXo 1 - Ficha de avaliação bateria de testes.

Teste 1: Suspensão por 5 segundos

\begin{tabular}{|l|l|l|}
\hline & 0 & não consegue suspender-se da cadeira de rodas e não realiza contração muscular \\
\hline & 1 & não consegue suspender-se da cadeira de rodas, mas realiza leve movimento com traço de contração \\
\hline & 2 & consegue suspender-se da cadeira de rodas, no entanto permanece por menos de cinco segundos \\
\hline & 3 & consegue manter-se suspenso da cadeira de rodas por cinco segundos \\
\hline
\end{tabular}

Teste 2: Transferência

\begin{tabular}{|l|l|l|}
\hline & 0 & Não consegue realizar a transferência de maneira autônoma \\
\hline & 1 & Consegue realizar a transferência de maneira autônoma \\
\hline
\end{tabular}

Teste 3: Resistência muscular bíceps

\begin{tabular}{|l|l|l|}
\hline & 0 & Realiza de 0 a 5 repetições \\
\hline & 1 & Consegue realizar 6 a 10 repetições \\
\hline & 2 & Consegue realizar 11 a 15 repetições \\
\hline & 3 & Consegue realizar mais de 16 repetiçôes \\
\hline
\end{tabular}

Quantas repetiçōes:

Teste 4: Resistência muscular tríceps

\begin{tabular}{|l|l|l|}
\hline & 0 & Realiza de 0 a 5 repetições \\
\hline & 1 & Consegue realizar 6 a 10 repetições \\
\hline & 2 & Consegue realizar 11 a 15 repetiçóes \\
\hline & 3 & Consegue realizar mais de 16 repetiçóes \\
\hline
\end{tabular}

Quantas repetiçóes: 
Teste 5: Alcance funcional lateral

\begin{tabular}{|l|c|l|}
\hline & 0 & Consegue alcançar a marca de 0 a $9,9 \mathrm{~cm}$ \\
\hline & 1 & Consegue alcançar a marca de 10 a $19,9 \mathrm{~cm}$ \\
\hline & 2 & Consegue alcançar a marca de $20 \mathrm{~cm}$ ou mais \\
\hline
\end{tabular}

Quantos:

Teste 5: Alcance funcional lateral abaixo

\begin{tabular}{|l|l|l|}
\hline & 0 & Não consegue ultrapassar o eixo da cadeira \\
\hline & 1 & Consegue ultrapassar o eixo da cadeira \\
\hline & 2 & Consegue encostar a ponta do dedo médio no chão \\
\hline
\end{tabular}

Teste 5: Alcance funcional frontal

\begin{tabular}{|c|c|l|}
\hline & 0 & consegue alcançar a marca de $0 \mathrm{a} 20 \mathrm{~cm}$ retornando à posição inicial com apoio na coxa \\
\hline & 1 & consegue alcançar a marca de $0 \mathrm{a} 20 \mathrm{~cm}$ retornando à posição inicial sem apoio na coxa \\
\hline & 2 & consegue alcançar a marca entre $21 \mathrm{a} 30 \mathrm{~cm}$ retornando à posição inicial com apoio na coxa \\
\hline & 3 & consegue alcançar a marca entre $21 \mathrm{a} 30 \mathrm{~cm}$ retornando à posiçáo inicial sem apoio na coxa \\
\hline & 4 & consegue ultrapassar a marca de $31 \mathrm{~cm}$ retornando à posiçáo inicial com apoio na coxa \\
\hline & 5 & consegue ultrapassar a marca de $31 \mathrm{~cm}$ retornando à posição inicial sem apoio na coxa. \\
\hline
\end{tabular}

Quantos:

Teste 5: Alcance funcional com rotaçáo de tronco

\begin{tabular}{|c|c|l|}
\hline & 0 & não consegue alcançar a marcação atrás do ombro em nenhum dos lados \\
\hline & 1 & consegue alcançar a marcação atrás do ombro em apenas um dos lados \\
\hline & 2 & consegue alcançar a marcação atrás do ombro em ambos os lados \\
\hline
\end{tabular}

Teste 6: Transpor degrau

\begin{tabular}{|l|l|l|}
\hline & 0 & náo consegue colocar as duas rodas da frente sobre a plataforma \\
\hline & 1 & consegue colocar as duas rodas da frente sobre a plataforma \\
\hline & 2 & consegue subir a cadeira sobre a plataforma \\
\hline & 3 & Consegue realizar subida e descida da plataforma \\
\hline
\end{tabular}

Teste 7: Tocar cadeira por $400 \mathrm{~m}$

\begin{tabular}{|c|c|l|}
\hline & 0 & não consegue realizar o percurso em menos de quatro minutos ou o realiza com mais de três interrupções \\
\hline & 1 & consegue realizar o percurso em menos de quatro minutos com uma a três interrupções \\
\hline & 2 & consegue realizar o percurso sem interrupçóes em tempo superior a quatro minutos \\
\hline & 3 & consegue realizar o percurso sem interrupçóes em tempo igual ou inferior a quatro minutos \\
\hline
\end{tabular}

Tempo:

ANExo 2 - Testes.

Teste 1 - Elevaçáo da cadeira de rodas por cinco segundos

Objetivos: Avaliar a resistência de membros superiores em isometria por curto período de tempo.

Justificativa: A permanência em suspensão da cadeira de rodas por cinco segundos é importante para se evitar a ocorrência de úlceras de pressão.

Materiais: cadeira de rodas e cronômetro.

Procedimentos: $\mathrm{O}$ avaliado deverá posicionar sua cadeira de rodas, com o freio acionado ou com a cadeira sendo segura no seu 
encosto por um auxiliar (avaliador), e realizar suspensão permanecendo nessa posição no período máximo de cinco segundos. Precauçôes de segurança: a superfície de realização do teste deverá ser antiderrapante e sem desníveis.

Observaçôes importantes: $\mathrm{O}$ avaliado deverá realizar duas tentativas como forma de aquecimento e familiarização com o movimento do teste e somente a terceira tentativa será considerada válida. Nas duas primeiras tentativas não é necessária à permanência por cinco segundos.

\section{Teste 2 - Transferência da cadeira de rodas}

Objetivos: Avaliar a capacidade do indivíduo em se transferir da cadeira de rodas para outro assento fixo que tenha a mesma altura do assento da cadeira do avaliado.

Justificativa: A independência nas transferências da cadeira de rodas é de extrema importância para pessoas com lesão medular, pois permite a independência para realização de atividades de cunho básico como, por exemplo, ir ao banheiro e realizar transferência da cadeira de rodas até o acento sanitário.

Materiais: cadeira de rodas, cadeira comum com encosto e sem apoio para os braços.

Procedimentos: o avaliado deverá posicionar sua cadeira de rodas, com o freio acionado ou com a cadeira sendo segura no seu encosto por um auxiliar (avaliador), a lado do assento em que irá realizar a transferência e com o auxílio dos membros superiores executar a tarefa. $\mathrm{O}$ assento no qual o avaliado fará a transferência deve ter as mesmas dimensóes de uma cadeira de rodas social, 40 a $55 \mathrm{~cm}$ de altura.

Precauçôes de segurança: certificar-se de que antes do início do teste a cadeira de rodas esteja com os freios acionados. A cadeira para a qual será realizada a transferência deve ter encosto elevado e será segura durante todo o procedimento pelo avaliador. Observaçóes importantes: Durante esse teste não poderá ser utilizado nenhum tipo de material de tecnologia assistiva como tábua de transferência, por exemplo.

\section{Teste 3 - Resistência muscular - bíceps}

Objetivos: Avaliar a resistência muscular de membros superiores de pessoas com lesão medular.

Justificativa: A resistência muscular de bíceps é de total relevância para pessoas com lesão medular, pois desempenha papel fundamental em atividades como tocar cadeiras, realizar suspensão e transferência.

Materiais: halter de dois quilos para mulheres e três quilos para homens.

Procedimentos: o avaliado deverá iniciar o movimento com o cotovelo estendido, segurando o halter com a mão (lado dominante) e em seguida realizar flexôes e extensóes do cotovelo repetindo o movimento o máximo de vezes que conseguir durante um período de 30 segundos.

Observaçóes importantes: Antes da realização do teste o individuo deverá realizar exercícios de alongamento e aquecimento dos principais grupamentos musculares que serão recrutados para realização do teste.

\section{Teste 4 - Resistência muscular - tríceps}

Objetivos: Avaliar a resistência muscular de membros superiores de pessoas com lesão medular.

Justificativa: A resistência muscular de tríceps, assim com a de bíceps é de total relevância para pessoas com lesão medular, pois desempenha papel fundamental em atividades como tocar cadeiras, realizar suspensão e transferência.

Materiais: halter de dois quilos para mulheres e três quilos para homens.

Procedimentos: Na realização do movimento para tríceps o avaliado utilizará o braço (lado dominante) para realização do teste. Nesse momento, o braço deverá estar posicionado paralelo à cabeça, com cotovelo estendido (posiçáo inicial), segurando o halter. $\mathrm{O}$ avaliado será instruído a realizar movimento de flexão do cotovelo para levar o halter atrás da cabeça e em seguida retomar a posiçáo inicial, repetindo o movimento o máximo de vezes que conseguir, durante o período de 30 segundos. Observaçôes importantes: Antes da realização do teste o individuo deverá realizar exercícios de alongamento e aquecimento dos principais grupamentos musculares que serão recrutados para realização do mesmo.

\section{Teste 5 - Alcance funcional dos braços}

Objetivos: Avaliar a capacidade do indivíduo de realizar alcance funcional em diferentes direçôes, frontal, lateral, acima, abaixo e com rotaçáo do tronco.

Justificativa: A possibilidade de execução de alcance funcional em diferentes direçóes viabiliza a pessoa com lesão medular maior independência na realização de atividades da vida diária sem a necessidade de dependência de outras pessoas. Materiais: cadeira de rodas, trena ou fita métrica.

Procedimentos: Este teste será subdividido em quatro categorias assim descritas: teste de alcance lateral, teste de alcance 
lateral abaixo, teste de alcance frontal e teste de alcance com rotação de tronco.

Precauçóes de segurança: certificar-se que antes do início do teste a cadeira de rodas esteja com os freios acionados e que o avaliado esteja preso de maneira confortável e seguro na cadeira.

Observaçôes importantes: o avaliado deverá realizar inicialmente duas tentativas para cada teste e apenas a terceira será considerada válida.

A trena ou fita métrica deve ser fixada na parede de acordo com a altura do acrômio do avaliado.

\subsection{Teste de alcance lateral}

Procedimentos: o avaliado será instruído a posicionar sua cadeira de rodas perto de uma parede de onde realizará o alcance funcional de braços na posição lateral. Para tanto, uma fita métrica ou trena deverá estar fixada à parede, posicionada na altura do acrômio do avaliado. Será solicitado ao participante que estenda o braço (lado dominante) com a palma da mão voltada para o lado de fora e o leve lateralmente o máximo que puder (FIGURA 1). O valor considerado será o que a $3^{\mathrm{a}}$ falange conseguir atingir. Serão realizadas três tentativas considerando sempre a medida de maior valor. Quanto ao outro braço/mão, o avaliado poderá fazer a opçáo de estabilizar o movimento que estará executando segurando o aro propulsor da cadeira de rodas do lado contrário.

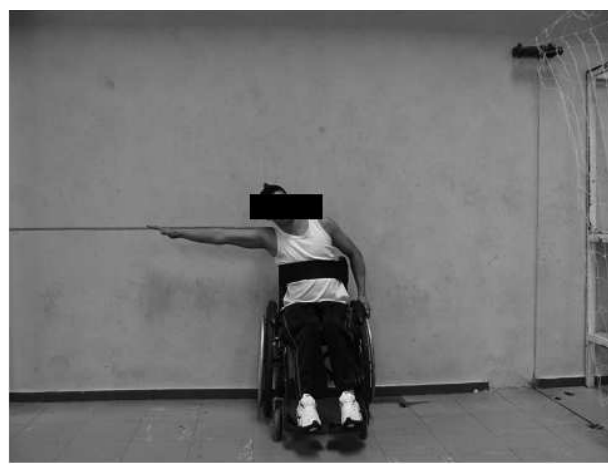

FIGURA 1 - Avaliado alcance teste de alcance lateral.

\subsection{Teste de alcance lateral abaixo}

Procedimentos: o avaliado será instruído a posicionar sua cadeira de rodas com os freios acionados em superfície não escorregadia e nivelada. Solicitar ao mesmo que com um dos braços (lado dominante) execute o movimento de inclinação lateral para baixo, conforme mostra a FIGURA 2. A mão do braço que não fará o movimento deve ficar posicionada sobre a roda da cadeira. O avaliado deverá executar essa ação por três vezes e destas será considerado o de melhor resultado.

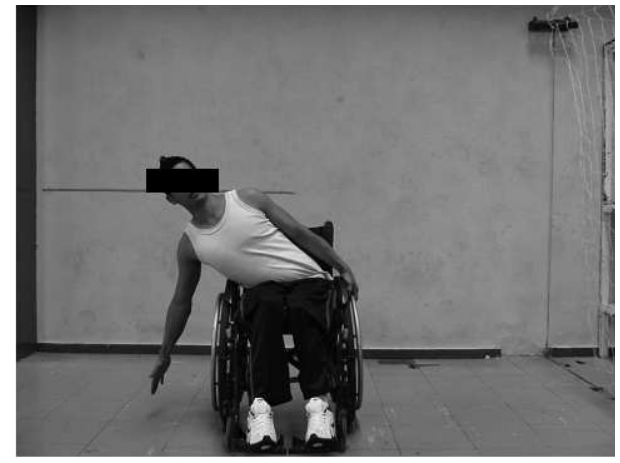

FIGURA 2 - Avaliado alcance teste de alcance lateral.

\subsection{Teste de alcance frontal}

Procedimentos: $\mathrm{O}$ avaliado será solicitado a permanecer sentado em sua cadeira de rodas, sem apoio para os membros superiores, posicionado lateralmente à parede, com o ombro distante $15 \mathrm{~cm}$ desta sem tocá-la em nenhum momento, com os pés paralelos numa posição confortável, mantendo o ombro próximo à parede flexionado a $90^{\circ}$. Com o auxílio de uma fita métrica ou trena que deverá ser fixada paralela ao chão, posicionado à altura do acrômio será realizada a medida inicial que corresponderá à posição em que o processo estiloide da ulna se encontrar nessa fita. $\mathrm{O}$ avaliado então será instruído a inclinar-se para frente, o máximo possível sem perder o equilíbrio, ou deslocar a cadeira de rodas. A outra mão, que não 
realiza o teste pode ou não estar posicionada em cima da coxa do avaliado (FIGURA 3). O deslocamento será mensurado sobre a fita métrica ou trena, com três tentativas de alcance funcional, levando em consideração apenas a de maior valor.

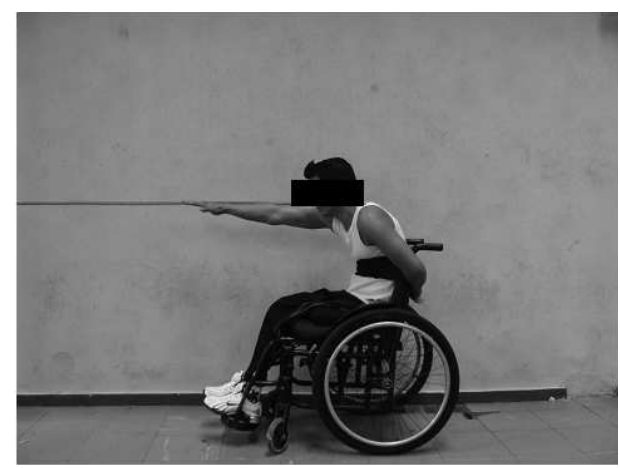

FIGURA 3 - Teste de alcance frontal.

\subsection{Teste de alcance com rotaçáo de tronco}

Procedimentos: neste teste o avaliado deverá executar o movimento de rotaçáo de tronco para trás. Para tanto, será fixada marcações atrás da cadeira do indivíduo logo abaixo das escápulas (ambos os lados). O outro braço, que não executa o movimento deve permanecer no local de preferência do avaliado. A FIGURA 4 ilustra em quais locais devem ser posicionadas as marcaçôes, bem como a execução desse movimento $\mathrm{O}$ avaliado deverá executar o mesmo movimento em três tentativas se na primeira não conseguir atingir a marcação.

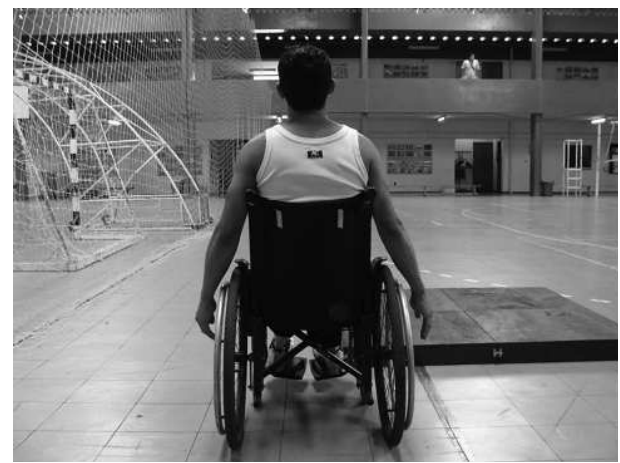

FIGURA 4 - Teste de alcance com rotação de tronco - marcações na cadeira de rodas, logo abaixo da região das escápulas.

\section{Teste 6 - Transpor degrau}

Objetivos: Avaliar a capacidade das pessoas com lesão medular de transpor obstáculos, como por exemplo, atravessar a rua e ultrapassar a guia da calçada quando esta não estiver nivelada adequadamente.

Justificativa: Indivíduos com lesão medular necessitam de independência para poder locomover-se sem auxílio de terceiros, principalmente para transpor obstáculos que encontram em qualquer trajeto que venham a percorrer.

Materiais: plataforma de madeira $(1,5 \mathrm{~m}$ x 1,5 $\mathrm{m}$ x $10 \mathrm{~cm})$, que suporte o peso e comporte o tamanho de uma cadeira de rodas. Procedimentos: $\mathrm{O}$ avaliado posicionado seguro e confortavelmente em sua cadeira de rodas será instruído a transpor a plataforma de madeira, que será alocada sobre placas de borracha para melhor estabilidade da mesma, evitando possíveis intercorrências. As rodas dianteiras devem ficar a uma distância máxima de $100 \mathrm{~cm}$ da plataforma.

O avaliado deverá iniciar esse teste dando um toque na cadeira como meio para impulsioná-lo auxiliando, dessa forma na execução da tarefa.

Precauçóes de segurança: O teste deverá ser realizado em lugar bem iluminado, com piso antiderrapante e nivelado. Os avaliadores deverão estar posicionados ao lado do avaliado em prontidão para possíveis intercorrências. A FIGURA 5 ilustra a execução do teste de transpor degraus. 


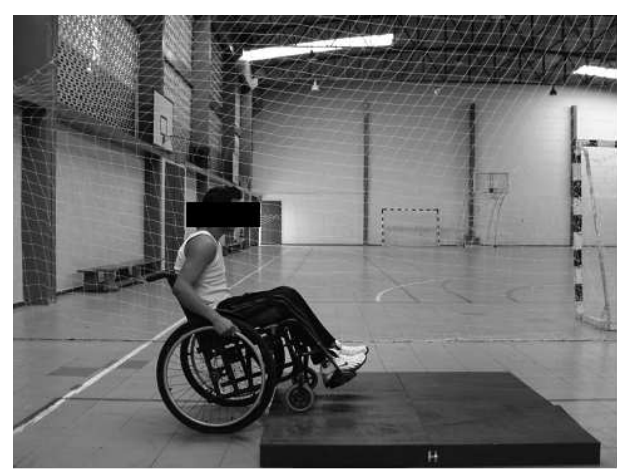

FIGURA 5 - Avaliado executando o teste de transpor degrau posicionando somente as rodas dianteiras sobre a plataforma.

\section{Teste 7 - Tocar cadeira de rodas $\mathbf{4 0 0}$ metros}

Objetivos: Avaliar a resistência geral da pessoa com lesão medular.

Justificativa: A resistência geral é de grande importância na vida da pessoa com lesão medular, sendo necessária para locomover-se com eficiência ao realizar atividades diárias como ir ao mercado ou passear.

Materiais: cronômetro, trena, cones, pista de atletismo ou quadra.

Procedimentos: o avaliado deverá tocar a cadeira de rodas por uma distância de 400 metros sem interrupção. Quando realizado em quadra, o percurso deverá ser construído de forma oval e suas margens devem ser delimitadas por cones, conforme FIGURA 6. A quadra deverá ter as dimensôes de $25 \times 15 \mathrm{~m}$, possibilitando a construção de um percurso de 80 metros. O avaliado nesse percurso deverá executar até cinco voltas totalizando 400 metros tocando a cadeira sem parar. O início e o final do percurso deverão ser demarcados com linhas no chão. Se for realizado na pista de atletismo, o teste deve ser iniciado em linha reta.

O avaliado deverá posicionar-se atrás da linha que demarca o início do percurso e, ao sinal “Atenção! Já!”, iniciar o toque da cadeira até completar a distância determinada. O desempenho será mensurado em tempo (minutos e segundos necessários para realização do percurso). O cronômetro deverá ser acionado ao sinal "Atenção! Já!" e, interrompido quando as rodas da cadeira ultrapassarem a distância determinada.

Precauçóes de segurança: a superfície de realizaçáo do teste deverá ser antiderrapante, sem desníveis, bem iluminada e a cadeira de rodas utilizada na execução do teste deverá ser a social ou esportiva com pneu de ar.

Observaçôes importantes: Antes da realização do teste o individuo deverá realizar exercícios de alongamento e aquecimento dos principais grupamentos musculares que serão recrutados para realização do teste.

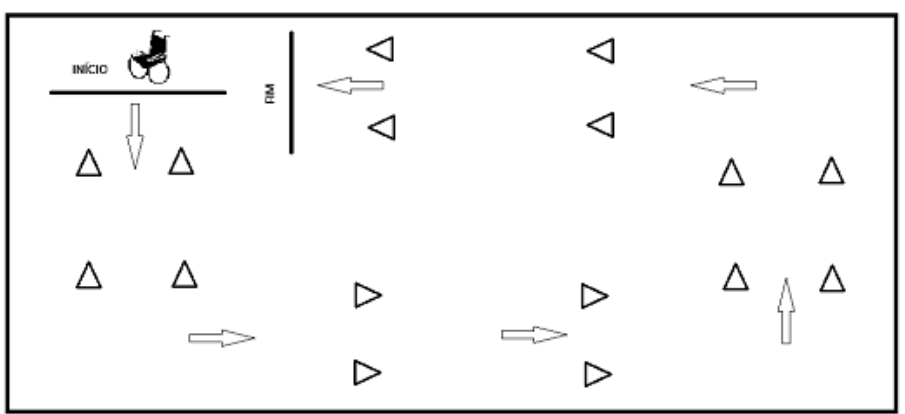

FIGURA 6 - Percurso do teste de tocar cadeira de rodas por 400 metros - quadra

ENDEREÇO

Camilla Yuri Kawanishi

Centro de Educação Física e Esporte

Universidade Estadual de Londrina

Rod. Celso Cid, km 380 - Campus Universitário

86057-970 - Londrina - PR - BRASIL e-mail: camilla_kawanishi@hotmail.com
Recebido para publicação: 15/05/2013

Revisado: 20/11/2013

Aceito: 07/02/2014 